\title{
Child Forensic Interviewing in Finland: Investigating Suspected Child Abuse at the Forensic Psychology Unit for Children and Adolescents
}

\section{Julia Korkman, Tom Pakkanen and Taina Laajasalo}

\section{Preamble}

In Finland, specialised university hospital units have taken on much of the role of the Barnahus in other Nordic countries, ensuring a childfriendly and expert environment for child interviews in cases of suspected crimes against children. The personnel consist of multi-professional teams including expertise in forensic psychology, paediatrics, child psychiatry and social work. There are units in the country's five university hospitals,

J. Korkman $(\bowtie) \cdot$ T. Pakkanen · T. Laajasalo

Helsinki University Central Hospital, Helsinki, Finland

e-mail: jkorkman@abo.fi

T. Pakkanen

e-mail: tom.pakkanen@hus.fi

T. Laajasalo

e-mail: taina.laajasalo@hus.fi

J. Korkman · T. Pakkanen

Åbo Akademi University, Turku, Finland 
thus covering the whole country. The units provide expert assistance when required by the police, in practically all cases involving preschool and young school-aged children as well as particularly vulnerable child victims. Finnish guidelines promote a hypothesis -testing approach and the use of expert interviewers (forensic psychologists with knowledge of human memory, child interviewing strategies, child development and suggestibility issues as well as the phenomena of child disclosure and trauma) within the pre-trial process, ensuring an evidence-based practice of investigating child abuse suspicions.

\section{Introduction}

In Finland, children under the age of 15 (and, as of 2016, in many cases 18) are not required to be present in court to testify. Instead, their testimony is usually recorded in the pre-trial (criminal) investigation. Interviews must be conducted according to best practice. Emphasis has been put on nationwide investigative interviewer training, including supervision and feedback. A particular feature of the Finnish system is the use of experts in forensic psychology within child abuse investigations. Another cornerstone within the Finnish system is the explicit use of a hypothesis-testing approach throughout the process.

Interviews with older children are normally conducted by the police, whereas preschool children, children with disabilities or communicational problems or children in cases that for other reasons are deemed to be particularly demanding are usually interviewed in the expert units. The units operate within the framework of the pre-trial investigation, and interviews within the units are monitored by the police in charge of the investigation but conducted by expert psychologists with training in forensic interviewing.

This chapter will present the legal and scientific framework of the units with a particular focus on the largest of these, the Child Forensic Psychology Unit at the University of Helsinki, founded in 2006 and inspired by the Icelandic Barnahus. The focus of the chapter is twofold: on the investigative interviews conducted by the forensic psychologists as well as the investigative process culminating in the expert statement delivered for the police and the court. 


\section{The Legal and Theoretical Framework for Assessing Allegations of Crimes Against Children in Finland}

In a famous Finnish case in the 1990s, a preschool-aged boy, "Niko", played games, which were perceived as sexual in nature, with his preschool friends. This led to a concern that Niko might have been sexually abused. Niko was interviewed and taken into custody. He was not allowed to live with his parents until years later, when it was realised that the allegation was most likely unfounded and that the investigative interview with Niko had been severely suggestive.

At the beginning of the 2000s, analyses of Finnish investigative interviews in cases of suspected child sexual abuse (CSA) showed that these were often highly suggestive (Korkman et al. 2008b). Similar findings were made in other Nordic countries (e.g. Cederborg et al. 2000; Thoresen et al. 2006; Thoresen et al. 2009), showing that investigative interviews were often of poor quality.

As the child interview is often the most important piece of evidence in an abuse investigation, the importance of a high-quality interview cannot be too strongly emphasised. Interviews of poor quality might in many ways risk the well-being of the child; in cases where abuse has not occurred, children may be removed from their families without due reason (false-positive errors), while in actual cases of abuse, poor interviews may fail to recognise actually occurring abuse (false-negative errors).

In Finland, the realisation that investigative child interviewing warrants particular skills led to the development of guidelines (Taskinen 2003; Duodecim 2013; Ellonen 2013), training (Lahtinen et al. in press) and the creation of the specialised units, to ensure a child-friendly and expert setting for investigating crimes against children (Law 2009). It was decided that the investigations would be clearly separated from therapeutic processes and that mental health professionals assisting the judicial system be specially trained for this task.

As children in Finland give their evidence during the pre-trial investigation, all interviews are electronically recorded and transcribed word 
for word, enabling careful analyses of the information provided. In order to ensure the right to a fair trial, the defendant may watch the recorded child interview and pose questions to the child through the interviewer.

\section{Evidence-Based Child Interviewing}

A forensic interview of a child is a developmentally sensitive and legally sound method of gathering factual information regarding allegations of abuse or exposure to violence. This interview is conducted by a competently trained, neutral professional utilizing research and practice-informed techniques as part of a larger investigative process (Newlin et al. 2015, 1).

Forensic child interviewing has been extensively researched, and there are widely endorsed best practice guidelines (e.g. Lamb et al. 2007). The most researched is the NICHD interviewing protocol, which is the standard in many countries (for an international review, including Finland and Norway, see LaRooy et al. 2015). The protocol improves the quality, and increases the amount, of reliable information in child interviews (e.g. Lamb et al. 2002, 2003; Sternberg et al. 2001), regardless of the child's age (Lamb et al. 2003). It is semi-structured and flexible and thus requires modification according to the suspicion at hand. This modification requires expertise on the part of the interviewer, and the interviews are thoroughly planned, bearing in mind the alternative hypotheses to the suspicion.

While the use of the NICHD protocol is associated with a lowered risk of false-negative errors (Lamb et al. 2007), the hypothesis-testing approach, and especially its application within the interview itself, may be considered a safeguard against false-positives errors and interviewer bias (Rohrabaug and London 2016). For instance, where the alternative hypothesis is that an abuse suspicion is the result of a parent coaching the child, the interviewer may pose questions about how the suspecting party found out about the allegation and how the child and this person have discussed the matter; especially in the case of older children, 
interviewers may also incorporate elements from other interview methods, in particular the cognitive interview (Memon et al. 2010; for an overview of different research protocols see, for example, Melinder and Korkman 2010).

Previous research (Korkman et al. 2008a; Lamb et al. 2003) has shown that the language used by child interviewers is often developmentally inappropriate. Children who witnesses in court have also reported that they didn't understand the language and that they experienced witnessing as traumatic (Plotnikoff and Woolfson 2004).

Needless to say, successful investigative interviews with children must fit the developmental level of the child. Children with problematic or developing communication skills may need expert assistance to communicate at their best level. An initial interview or linguistic assessment may be carried out with young children or children who have developmental difficulties, to assess the child's capacities as a witness. Tools (dolls, body diagrams) are not recommended or used in Finland (as recommended by research, see, for example, Poole et al. 2011; Poole and Dickinson 2011); however, the child may draw (e.g. an overview of the building) and write within the interview as a supplement to the verbal account.

While research previously cautioned against the repeated interviewing of children, underlining the risks associated with repeated suggestive interviewing (e.g. Bruck and Ceci 2004; Melnyk and Bruck 2004), recent research indicates that conducting more than one interview can have advantages in terms of an increase in information (LaRooy et al. 2008). One of the key concepts behind the Barnahus model is avoiding a secondary traumatisation of the child, which may occur, for instance, if the child is forced to talk about the abuse repeatedly to different agencies. This is also emphasised in the Children's Advocacy Centres (CACs) literature in the USA, stating that "CACs have aimed to change the practice of forensic child interviewing by coordinating multiple investigations, limiting the number of interviews and interviewers children have, and providing "child friendly" locations for interviews" (Cross et al. 2007, 1032). This evaluation of CAC interviews notes that children are usually interviewed once or twice in the CAC and in the vast majority of cases by the same interviewer. 
Guidelines in Finland are flexible with regard to the number of interviews per child, and children in the Helsinki unit are (2006-2012) interviewed twice on average. Recent US recommendations suggest that more than one interview may be necessary to ensure children are given a real opportunity to communicate their experiences; however, importantly, they note that the risks associated with repeated questioning must be acknowledged and that potentially repeated interviews should always be conducted appropriately (i.e. not suggestively): "However, some children require more time and familiarity to become comfortable and to develop trust in both the process and the interviewer. Recent research indicates that multiple interview sessions may allow reluctant, young, or traumatized children the opportunity to more clearly and completely share information" (Cross et al. 2007, 11).

\section{Conducting Child Abuse Assessments in University Hospital Units}

University hospital teams consist of experts in forensic and developmental psychology, social workers familiar with child protection, child psychiatrists and paediatricians specialised in the field. The units serve as multiprofessional sites where all the information concerning a particular child can be shared among the police, health care and social work professionals in order to make informed decisions about how to proceed in a situation where an abuse allegation has been raised. The premises are child friendly, with a waiting room furnished with play areas with toys, books, games and magazines. The interview room itself is calm, with pleasant furniture but avoiding an abundance of stimuli (as recommended by, for instance, Poole and Lamb 1998, as these may distract the child).

The expert assistance can take many forms depending on the case under investigation. One of the central roles is to assist the police in conducting interviews with young children or children with disabilities. Psychologists with training in child development and forensic interviewing conduct the interviews within the units. The police and other professionals (e.g. the child's attorney, the prosecutor, a child psychiatrist, the defence lawyer) follow the interviews live through a video-link. 
The police also turn to the units in particularly complicated cases, such as severe custody disputes. Custody disputes are arguably among the most complicated circumstances in which to investigate abuse allegations, it is necessary in virtually all cases to consider the possibility that the child(ren) may have been manipulated or coached (Hendershot and Bow 2013).

Since the founding of the specialised units, collaboration with the police has developed to include a wide range of collaboration forms. The unit can consult for or supervise the police in planning and conducting the interview as well as give feedback on interviews, something which has the long-term benefit of strengthening expertise within the police (Lamb et al. 2002).

In many cases, the units write expert statements for the purpose of the judicial process. Within these statements, the background of the allegation is detailed along with the alternative hypotheses formulated for the suspected abuse. The collected facts are then analysed, and the different hypotheses are weighed against these. The statements do not include opinions on whether a crime has occurred or not and are not binding in the court, but may serve as important information in the cases (see, for example, the Finnish Supreme Court decision 2014: 48). ${ }^{1}$

\section{Cases at the Helsinki Unit Between 2006 and $2012^{2}$}

During the first 6 years, 224 children were interviewed at the Helsinki unit. $^{3}$ The children were 3-16 years, with more than half (55\%) below the age of 7. More than half of the interviewed children had psychological, neurological or developmental difficulties. In $25 \%$ of the cases, a custody dispute preceded the suspicion. Many of the families had problems related to substance abuse, mental health problems and/or a history with the child welfare services. The hospital units investigate both physical and sexual abuse allegations, although initially, emphasis was on child sexual abuse cases as these were deemed to be particularly challenging. Below is an overview of the child sexual abuse allegations assessed between 2006 and 2012 . 
In $45 \%$ of the suspected child sexual abuse cases, the suspect was the child's biological father, in 35\% a person outside the family and in 5\% a stepfather. It is important to note that according to research, child sexual abuse committed by a biological father is uncommon compared to other perpetrators ( $0.02 \%$; Fagerlund et al. 2014 86-87). In cases of suspected physical abuse, the father was the most common suspect, followed by the mother.

When observing the outcomes of the assessments (Korkman et al. 2012), the child sexual abuse hypothesis was confirmed in $1 / 4$ of the cases, while in $1 / 2$ of the cases, a rivalry hypothesis received more support (in the remaining $1 / 4$ of the cases, the outcome of the investigation remained inconclusive). The child sexual abuse cases which were least likely to be confirmed involved preschool (<7yrs) children, custody disputes, a suspected biological father and the non-existence of other evidence for the suspected abuse. Importantly, while more than $70 \%$ of the children interviewed were deemed in need of assessment or therapy, this need was equally great among children in cases assessed to be unfounded. This implies that rather than seeing psychological symptoms as indicators of abuse, they can also lead to or be the result of unfounded suspicions.

\section{The Investigative Method at the Helsinki Unit}

Key elements of the Finnish model of assessing child abuse allegations are explained below, along with case examples to describe the methods used in practice.

\section{Formulating Alternative Hypotheses to the Allegation}

It is recommended that investigators in Finland use a hypothesis-testing approach (Current Care Guidelines 2013; Ellonen 2013). After carefully assessing the available background information, alternative hypotheses to the suspected abuse are formulated (e.g. Poole and Lamb 1998; Rohrabaugh et al. 2016). The approach follows the principle stated by Dale and Gould (2014) who advocate for a "neutral, objective, and 
even-handed hypothesis-testing stance" by forensic experts and stress the need to use "appropriate interviewing techniques, data collection from multiple sources, and consideration of multiple hypotheses" (ibid., 171).

Within the initial assessment of the case, particular attention is paid to how the allegation came about, risk factors for abuse, identifying potential risks for pre-interview suggestion or misunderstandings, wrong interpretations or deliberate lies, and so on. Examples of alternative hypotheses in cases of suspected child sexual abuse may include (see Herman 2009):

- Child sexual abuse has occurred.

- The allegation has arisen from a misunderstanding (e.g. the suspect was helping the child wash).

- The child has seen porn/sexual material and, therefore, has knowledge about adult sexuality.

- The child's account is due to repetitive suggestive discussions with an adult (e.g. custody disputes).

- The child is lying (e.g. to cover up their own shame when getting caught masturbating).

In acute cases, where there are injuries or photo/video evidence, the focus is on interviewing the child as quickly as possible; however, in cases where a long time has passed since the alleged events, the need for thorough information collecting and analysis is stronger and the need to interview the child is not deemed as acute as in a recent case.

Acknowledging different possible hypotheses at the outset of the investigation is in the best interests of the child: if a suspicion is unfounded, the child will not be traumatised by, for instance, being unduly removed from their parents. Also, if all other relevant hypotheses to an allegation have been carefully addressed, the interview is more likely to be considered reliable evidence in court.

The case ${ }^{4}$ below illustrates how alternative hypotheses are formulated in a case of suspected child physical abuse.

A five-year-old boy, whose parents had separated, returned from a stay with his mother with a bruised cheek. According to the father, the boy 
said his mother had hit him. The father filed a police report. The parents had divorced two years earlier, after which their relationship had been strained. A family court had ordered the boy to live with his mother with visits to his father. The parents had previously accused one another of physical abuse. Based on the initial information, three hypotheses were formulated: (1) the boy had been physically abused by his mother, (2) the suspicion was due to a misunderstanding between the father and the son, fuelled by the hostile relationship between the parents and (3) the child fabricated an account of physical abuse to gain attention or approval from his father. Because of the possible effect of the parent's tense relationship on the boy, it was decided that both parents would take turns to take the boy to his interviews.

The boy came to his first interview with his mother. When asked about the bruise on his cheek, he replied that he had fallen with his kick-bike and hurt his face. At his second interview with his father, the boy said his mother had hit him in the face. When the interviewer then asked if the hitting had left any marks, the boy referred to the bruise on the cheek. When confronted with the discrepancy in his accounts, the boy said the bruise was from his mother hitting him and that he didn't know why he had told the interviewer otherwise previously. In his third interview, when again brought by his mother, the boy told the interviewer that the bruise was from when he had fallen. When he again was confronted with the discrepancy in his accounts, he gave additional details about the situation where he had fallen. The conclusion was that all the tested hypotheses were supported to some degree, and thus, the outcome of the investigation was inconclusive. It should be noted that there were no reports made to persons outside the immediate family indicating physical abuse by either parent; instead, there was much concern about the effects of the difficult relationship between the parents on the boy's development. The parents were provided with psycho-education about the effects of an ongoing parental dispute on children and the means to handle their strained relation better.

In cases such as this, the possible contamination of the child's account needs to be taken into consideration when planning and conducting the interview. Had this child only been interviewed when accompanied by one particular parent, the investigation would possibly have been severely 
flawed. In many Barnahus (e.g. Stockholm), children are often accompanied by persons other than the parents (for instance, a support person from the school or similar) to the interview, which is likely to reduce the risk of immediate pre-interview contamination, at least to some extent.

\section{Assessing the Emergence and Background Information of the Suspicion}

Suspicions of child abuse form a diverse array of cases, and no one procedure can cater for all cases. Instead, investigations must be flexible and when necessary, very quick in operation. Some suspicions are vague and require thorough assessments of the background information. Information concerning the child and the suspicion provided by the child welfare services, healthcare information and information from the school or kindergarten and so on may differentiate long-lasting abuse and neglect from single instances of less severe forms of abuse. The background information helps direct the interventions undertaken in line with the best interests of the child. In acute cases, the priority is on hearing the child immediately, rather than gathering large amounts of background information.

One of the most important phases when investigating an abuse suspicion is the screening of background information to assess whether there is a cause for suspecting abuse. In cases of suspected child sexual abuse, Faust and colleagues state that "the great majority of errors in the detection of sexually abused children occur during Phase 1 or screening. Every sexually abused child who is not referred is a certain error. Every nonabused child who is referred is a potential error, and some of these potential errors turn into actual ones during Phase 2 or evaluation. ... there is essentially no question that a fairly substantial percentage of nonabused children referred for evaluation are misidentified as abused" (Faust et al. 2009, 51).

Thoroughly taking into account alternative explanations for the abuse is also in the interest of all counterparts, not least the possible child victim. In cases where the child has indeed been victimised, a proper investigation should leave as little doubt as possible as to the events. Below is a description of a case where there was no other evidence for the sexual 
abuse than a little girl's account of a situation more than one year ago. A thorough examination of the alternative hypotheses and the background to the allegation, however, led to the conclusion that the child sexual abuse hypothesis was confirmed and no alternative hypotheses gained support. The court sentenced the suspected grandfather, largely based on the child's interview and the expert testimony.

A five-year-old girl had lived at a children's home for almost a year, having been removed from her biological single-parent mother due to the mother's severe substance abuse. The girl had adjusted well to the children's home.

When discussing fears one evening, the girl had spontaneously told a member of the personnel that she once was scared when visiting her grandfather, because he had locked her with him in the toilet and told her to suck his penis. As other children approached, the employee did not ask any further questions about this. Later, she asked the girl who she had meant when she said she had been scared in the toilet. The girl answered the name of her maternal grandfather, whom she hadn't seen for almost a year. The personnel consulted the Helsinki unit, and it was recommended that no further questions be asked. The police started an investigation, and the girl was brought to the unit for an interview within the following days. The alternative hypotheses formulated were (1) that the grandfather had sexually abused the girl (or attempted to), (2) that the personnel had misunderstood the girl's utterance or (3) that the girl had used words relating to adult sexuality without fully understanding what they meant.

The girl's linguistic and memory skills were assessed through both practice interviews and with some neuropsychological testing, as the event in question was remote in time and the girl was very young. She had above average verbal and memory skills and was capable of giving detailed descriptions of events experienced months earlier. The topic of the interview was introduced by referring to her discussion of fears with the member of the personnel. The girl reported that around Christmas almost one year earlier, she had been left alone with her grandfather who took her to the toilet and tried to engage her in oral sex. The description was detailed and typically childish in its non-understanding of sexual elements, and the girl said she had told the mother at the time. When the police interviewed the mother, she confirmed this. 


\section{Screening the Cases: When Children Are not Interviewed}

When the suspicion is deemed non-indicative of abuse, for instance, based on the behaviour that is age typical (see Poole and Wolfe 2009) or likely due to other factors in the child's life, children may not be interviewed at all. This is true also when the child does not have the developmental ability for an interview, or the abuse is suspected to have taken place in early infancy before autobiographical memories are formed (i.e. before language development; Greenhoot and Tsethlikai 2009).

In cases where the child has been repeatedly interviewed, re-interviewing may not be in their best interests. This may be the case particularly when there is evidence that the child has been subjected to suggestive questioning prior to the investigation. There are cases where caretakers provide agencies with their own recorded "interviews" (as proof of what the child has said), and these may at times be suggestive to the point that a child's statement is clearly contaminated (for an analysis of such cases, see Korkman et al. 2014). In some of those cases, the child has been asked the same leading questions (e.g. "did X touch you between the legs?") almost 20 times.

Below is a short description of a case where the child was too young to be able to give a full account of the worrying physical signs that led to a suspicion of severe physical abuse.

The kindergarten noticed severe scratches on the arm of a boy who was almost four years old, which they thought looked like someone had grabbed the boy's arm. The boy was asked about the scratches. He said the family dog had caused them. The kindergarten did not believe him and reported a suspicion of physical abuse to the child welfare services. The child welfare services thought that the bruising looked like signs of physical abuse, and when asking the boy whether someone had hurt his arm, he had answered affirmatively (according to the child welfare services' files). When asked who had grabbed him, the boy replied "dad". The child welfare services filed a police report, and the boy was medically examined. At the first doctor's appointment, the boy told the doctor his father had grabbed his arm. The child welfare services took the boy into custody and the police referred the case to the Helsinki unit. Based on the available information, three alternative hypotheses were formulated: 
(1) the bruising on the boy's hand was due to physical abuse by the father,

(2) the account of physical abuse had evolved as a result of suggestive questioning and (3) the scratches on his arm were due to (a) violent play with the family dog or with (b) other children (as the boy's mother had stated). When assessing the boy's linguistic capabilities, it became apparent that he did not possess the prerequisites to give reliable accounts of experiences. He also seemed prone to suggestion, answering questions he did not understand with "yes". While the child was unable to give a verbal account of how he had gotten the scratches, the plausibility of the hypothesis that the scratches were caused by the family dog could be tested. The police visited the boy at home and videotaped the boy playing with the dog. The dog (a dachshund puppy) made several lunges at the boy, biting his forearms where the scratches had been. It was concluded that the hypothesis about violent play with the dog and an account formed by repeated suggestive questioning (the initial response the boy had given was that the dog had caused the bruising) was most likely, and the outcome of the investigation was that the suspicion of child abuse was not founded.

As in this case, many of the children referred to the unit by the police are too young to possess the developmental prerequisites for giving a detailed enough account of their experiences. Here, the collaboration between different professionals and the thorough examination of other evidence is of crucial importance.

\section{Support for the Children and Families}

Assessments are made in close cooperation with the police and the child welfare services, guaranteeing timely interventions and support. After the assessment, the outcome of the interview and the assessment is discussed with the parents. Parents are informed about the continuation of the judicial process, and their worries about the child's recovery are discussed. Parents are also notified about where to find further support. The child's need for psychiatric support is assessed, and when necessary, the unit's child psychiatrist makes a referral to treatment (typically to family welfare units or child psychiatric units). In addition to the services provided outside the unit, the unit provides trauma-focused 
cognitive-behavioural therapy (Tf-CBT) for a number of children and their families. Tf-CBT is an evidence-based short-term treatment developed especially for victims of child sexual abuse (Ramirez de Arellano et al. 2014).

\section{Concluding Remarks and Future Directions}

While the Finnish system caters well for the youngest and most vulnerable witnesses, concern remains that older children who are interviewed by the police may not be directed to treatment or care, nor are police interviews necessarily done in child-friendly premises. There is currently a project (called Barnahus) that is ongoing in Finland, aiming to ensure that all children be interviewed in child-friendly settings, including older children and teenagers who are, at present, commonly interviewed by the police, at a police station, and that their possible need for further support be assessed.

Among the benefits of the Finnish system that the authors would like to stress, and which could easily be implemented into the praxis of other countries and to the different Barnahus developments, are the use of (forensic) psychological expertise within the pre-trial investigation and the hypothesis-testing approach.

Young children and children with special needs require particular expertise on the part of the interviewer. Children with developmental disorders such as ADHD or autism spectrum disorders particularly require an in-depth understanding of the neuropsychological elements of the children's functioning in order to facilitate their recollections. The opportunity to obtain assistance in complex cases has been greatly appreciated by the police, and collaborating with the expert unit has also served as a source of re-education for the police officers.

The fact that the expert units have the right to gather all information about the children is of vital importance. Only by closely examining child welfare services' reports, healthcare documentation and information by school or day care personnel, the risk of, for instance, long-term violent abuse can be assessed. The hypothesis-testing approach, when applied through the whole investigation-from the assessment of the 
emergence of the suspicion to the conclusions drawn based on all the gathered facts - minimises the risk of the critical problems of confirmation bias and leading interviewing styles. This helps guide investigators towards the truth behind a suspicion-be it founded or unfounded. It seems fair to assume that it is in the best interests of the child that criminal investigations rely on evidence-based practices, minimising the risk of wrong outcomes. When investigations are properly conducted, they can and should fulfil both the requirements of a fair trial and at the same time be sensitive to the particular needs of child witnesses and victims.

\section{Notes}

1. One weakness and point of critical discussion in the current Finnish system concern the availability of second opinions. Expert statements are not as readily available for all parties: only the police, prosecutor or the court can ask the units for an official statement.

2. The data were collected as part of an ongoing research project, which has been approved by the ethical committee of the Helsinki University Central Hospital and the National Police Board.

3. The following years have shown a steady increase in the number of cases and interviewed children as the unit has expanded from a personnel consisting of six professionals in 2006 to 19 in 2015. The number of investigations in 2011 was 118 ; in 2012, there were 145; in 2013, there were 151; in 2014, there were 203; and in 2015, there were 246.

4. All the case vignettes presented in this chapter have been thoroughly anonymised in order to protect the identity of all the parties involved.

\section{References}

Bruck, Maggie, and Stephen Ceci. 2004. Forensic developmental psychology. Unveiling four common misconceptions. Forensic Developmental Psychology 13: 229-232.

Cederborg, Ann-Christine, Yael Orbach, Kathleen Sternberg, and Michael E. Lamb. 2000. Investigative interviews of child witnesses in Sweden. Child Abuse and Neglect 24: 1355-1361. 
Cross, Theodor P., Lisa M. Jones, Wendy A. Walsh, Monique Simone and David Kolko. 2007. Child forensic interviewing in Children's Advocacy Centers: Empirical data on a practice model. Child Abuse and Neglect 31: 1031-1052.

Dale, Milfred, and Jonathan W. Gould. 2014. Commentary on "Analyzing Child Sexual Abuse Allegations": Will a New Untested Criterion-Based Content Analysis Model be Helpful? Journal of Forensic Psychology Practice 14: 169-182.

de Arellano, Ramirez, A. Michael, Russell Lyman, Lisa Jobe-Shields, Preethy George, Richard H. Dougherty, Allen S. Daniels, Sushmita Ghose, Larke Huang, and Miriam E. Delphin-Rittmon. 2014. Trauma-Focused Cognitive Behavioral Therapy: Assessing the Evidence. Psychiatric Services 65: 591-602.

Duodecim (the Finnish Medical Society). 2013. Current Care Guidelines: Investigating Suspicions of Child Sexual Abuse. http://www.kaypahoito.fi/ web/kh/suositukset/suositus;jsessionid=7E3A7E56839CC04A143BED0D A7F6BD97? id=hoi34040.

Ellonen, Noora. (ed.) 2013. Rikostutkinta lapsiin kohdistuvissa väkivalta- ja seksuaalirikoksissa (Investigating sexual and violent crimes against children). Poliisiammattikorkeakoulun oppikirjat 20.

Fagerlund, Monica, Marja Peltola, Juha Kääriäinen, Noora Ellonen and Heikki Sariola. 2014. Lasten ja nuorten väkivaltakokemukset 2013 (in Finnish). https://www.theseus.fi/bitstream/handle/10024/86726/Raportteja_110_ lapsiuhritutkimus_web.pdf.

Faust, David, Ana J. Bridges and David C. Ahern. 2009. Methods for the Identification of Sexually Abused Children. Suggestions for Clinical Work and Research. In The Evaluation of Child Sexual Abuse Allegations. A Comprehensive Guide to Assessment and Testimony, ed. Kathryn Kuehnle and Mary Connell, 3-19. Wiley: Hoboken, New Jersey.

Finnish Supreme Court decision. 2014. A decision concerning a child sexual abuse allegation. http://korkeinoikeus.fi/fi/index/ennakkopaatokset/precedent/1404215595714.html.

Greenhoot, Andrea F., and Monica Tsethlikai. 2009. Repressed and Recovered Memories During Childhood and Adolescence. In The Evaluation of Child Sexual Abuse Allegations. A Comprehensive Guide to Assessment and Testimony, ed. Kathryn Kuehnle and Mary Connell, 203-244. Wiley: Hoboken, New Jersey.

Hendershot, Lesly, and James N. Bow. 2013. Investigating Sexual Abuse Allegations in Child Custody Cases. American Journal of Forensic Psychology 31: 37-53. 
Herman, Steve. 2009. Forensic Child Sexual Abuse Evaluations. Accuracy, Ethics, and Admissibility. In The Evaluation of Child Sexual Abuse Allegations. A Comprehensive Guide to Assessment and Testimony, ed. Kathryn Kuehnle and Mary Connell, 247-266. New Jersey: Wiley.

Korkman, Julia, Aino Juusola, and Pekka Santtila. 2014. Who made the disclosure? Recorded conversations between children and caretakers suspecting child abuse. Psychology, Crime and Law 20: 994-1004.

Korkman, Julia, Pekka Santtila, Tove Drzewiecki, and N. Kenneth Sandnabba. 2008a. Failing to Keep it Simple: Language Use in Child Sexual Abuse Interviews with 3-8-Year-Old Children. Psychology, Crime and Law 14: 41-60. Korkman, Julia, Pekka Santtila, Malin Westeråker, and N. Kenneth Sandnabba. 2008b. Interviewing Techniques and Follow-Up Questions in child Sexual Abuse Interviews. European Journal of Developmental Psychology 5: 108-128. Korkman, Julia, Taina Laajasalo, Katarina Finnilä, Merja Oksanen and Eeva Aronen. 2012. Investigating suspicions of child sexual abuse. (Lapsen seksuaalisen hyväksikäyttöepäilyn selvittäminen). Suomen Lääkärilehti Duodecim 20/2012. Lahtinen, Hanna, Julia Korkman, Aarno Laitila and Lauri Mehtätalo. In press. The Effect of Training on Investigative Interviewers' Attitudes and Beliefs Related to Child Sexual Abuse. Investigative Interviewing: Research and Practice. Lamb, Michael E., Irit Hershkowitz, Yael Orbach and Philip Esplin. 2007. Tell Me What Happened: Structured Investigative Interviews of Child Victims and Witnesses. Wiley Series in Psychology of Crime, Policing and Law.

Lamb, Michael E., Kathleen Sternberg, Yael Orbach, Philip Esplin, and Susanne Mitchell. 2002. Is Ongoing Feedback Necessary to Maintain the Quality of Investigative Interviews with Allegedly Abused Children? Applied Developmental Science 6: 35-41.

Lamb, Michael E., Kathleen Sternberg, Yael Orbach, Philip Esplin, Heather Stewart, and Susanne Mitchell. 2003. Age Differences in Young Children's Responses to Open-Ended Invitations in the Course of Forensic Interviews. Journal of Consulting and Clinical Psychology 71: 926-934.

Lamb, Michael E., Yael Orbach, Irit Hershkowitz, Philip W. Esplin, and Dvora Horowitz. 2007b. Structured Forensic Interview Protocols Improve the Quality and Informativeness of Investigative Interviews with Children: A Review of Research Using the NICHD Investigative Interview Protocol. Child Abuse and Neglect 31: 1201-1231.

LaRooy, David, Michael E. Lamb and Margaret-Ellen Pipe. 2008. Repeated Interviewing: A Critical Evaluation of the Risks and Potential Benefits. In The Evaluation of Child Sexual Abuse Allegations. A Comprehensive Guide to Assessment and Testimony, ed. Kathryn Kuehnle and Mary Connell, 327-361. Hoboken: Wiley. 
LaRooy, David, Sonja Brubacher, Anu Aromäki-Stratos, Mireille Cyr, Irit Hershkowitz, Eynkung Jo, Julia Korkman, Lindsey Malloy, Trond Myklebust, Moriko Naka, Carlos Peixoto, Kim Roberts, Heather Stewart, and Michael E. Lamb. 2015. The NICHD Protocol: A Review of an Internationally-used Evidence-Based Tool for Training Child Forensic Interviewers. Journal of Criminological Research, Policy and Practice 1: 76-89.

Law Concerning the Investigations of Sexual and Physical Abuse Against Children. 2009. 2013 (in Finnish: http://www.finlex.fi/fi/laki/ajantasa/2008/20081009).

Melinder, Annika, and Julia Korkman. 2010. Children's Memory and Testimony. In Forensic Psychology in Context: Nordic and International Approaches, ed. P.A. Granhag, 117-138. UK: Willan Publishing.

Melnyk, Laura and Maggie Bruck. 2004. Timing moderates the effects of repeated suggestive interviewing on children's eyewitness memory. Applied Cognitive Psychology 18: 613-631.

Memon, Amina, Chris A. Meissner, and Joanne Fraser. 2010. The Cognitive Interview: A Meta-Analytic Review and Study Space Analysis of the Past 25 Years. Psychology, Public Policy, and Law 16: 340-372.

Newlin, Chris, Linda C. Steele, Andra Chamberlin, Jennifer Anderson, Julie Kenniston, Amy Russell, Heather Stewart and Viola Vaughan-Eden. 2015. Child Forensic Interviewing: Best Practices. Juvenile Justice Bulletin, U.S. Department of Justice. http://www.ojjdp.gov/pubs/248749.pdf.

Plotnikoff, Joyce and Richard Woolfson. 2004. In their own words: The experiences of 50 young witnesses in criminal proceedings. Policy Practice Research Series, NSPCC Publications, London.

Poole, Debra Ann, Maggie Bruck, and Margaret-Ellen Pipe. 2011. Forensic Interviewing Aids: Do Props Help Children Answer Questions About Touching? Current Directions in Psychological Science 20: 11-15.

Poole, Debra Ann, and Jason J. Dickinson. 2011. Evidence Supporting Restrictions on Uses of Body Diagrams in Forensic Interviews. Child Abuse and Neglect 35: 659-669.

Poole, Debra Ann, and Michele A. Wolfe. 2009. Child Development: Normative Sexual and Nonsexual Behaviors That May Be Confused with Symptoms of Sexual Abuse. In: The Evaluation of Child Sexual Abuse Allegations. A Comprehensive Guide to Assessment and Testimony, ed, Kathryn Kuehnle and Mary Connell, 101-128. Hoboken, New Jersey: Wiley.

Poole, Debra Ann, and Michael E. Lamb. 1998. Investigative Interviews of Children. A Guide for Helping Professionals. Washington D.C.: American Psychological Association.

Rohrabaugh, Monica, Kamala London and Ashley K. Hall. 2016. Planning the Forensic Interview. In Forensic Interviews Regarding Child Sexual Abuse. 
A Guide to Evidence-Based Practice, ed. W.T. O'Donohue and M. Fanetti, 197-218. Switzerland: Springer International Publishing.

Sternberg, Kathleen J., Michael E. Lamb, Graham M. Davies and Helen L. Westcott. 2001. The Memorandum of Good Practice: Theory versus application. Child Abuse and Neglect 25: 669-681.

Taskinen, Sirpa. 2003. Recommendations by an Expert Group for Social Health and Welfare Personnel. Investigating Child Sexual and Physical Abuse (in Finnish). Gummerus Kirjapaino Oy.

Thoresen, Christian, Kyrre Lønnum, Annika Melinder, and Svein Magnussen. 2009. Forensic Interviews with Children in CSA Cases: A Large-Sample Study of Norwegian Police Interviews. Applied Cognitive Psychology 23: 99-1011.

Thoresen, Christian, Kyrre Lønnum, Annika Melinder, Ulf Stridbeck, and Svein Magnussen. 2006. Theory and Practice in Interviewing Young Children: A Study of Norwegian Police Interviews 1985-2002. Psychology, Crime, and Law 12: 629-640.

Open Access This chapter is licensed under the terms of the Creative Commons Attribution 4.0 International License (http://creativecommons. org/licenses/by/4.0/), which permits use, sharing, adaptation, distribution and reproduction in any medium or format, as long as you give appropriate credit to the original author(s) and the source, provide a link to the Creative Commons license and indicate if changes were made.

The images or other third party material in this chapter are included in the chapter's Creative Commons license, unless indicated otherwise in a credit line to the material. If material is not included in the chapter's Creative Commons license and your intended use is not permitted by statutory regulation or exceeds the permitted use, you will need to obtain permission directly from the copyright holder.

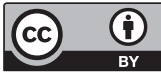

